\title{
usA Pdentificication of Added Value ITS Services using Concept Mapping Techniques
}

\author{
M. R. Martínez Torres, C. Díaz-Fernández \\ E. U. Estudios Empresariales \\ University of Seville \\ Seville, Spain \\ \{rmtorres,cardiaz\}@us.es
}

\author{
S.L. Toral, F. Barrero, F. Cortés \\ E. S. Ingenieros \\ University of Seville \\ Seville, Spain \\ \{toral,fbarrero\}@esi.us.es
}

\begin{abstract}
The evolution of electronics and the growing capabilities of in-vehicle and public infrastructure equipments make feasible the development of new value added services in the field of Intelligent Transportation Systems. However, initiatives in this sense frequently failed due to the lack of agreement or coordination among service providers, public authorities and final users. This paper proposes a scientific method based on concept mapping techniques to extract these added value services. The main benefit of the proposed methodology is its ability to take into account the different points of view of the main actors involved in the field of transport. Obtained results provide general guidelines for future development of ITS services.
\end{abstract}

Keywords-ITS services; concept mapping; multidimensional scaling; cluster analysis

\section{INTRODUCTION}

Intelligent Transportation Systems (ITS) is a worldwide initiative "concerned with the application of electronic information and control in improving transport" [1]. ITS should be considered as a multidisciplinary area of research due to the variety of actors involved and the diversity of its applications. Today, ITS can offer a variety of technological solutions to the growing surface transportation problems being experienced by more and more cities in the world, alleviating congestion and increasing road capacities [2]. But ITS has also important implications on safety and citizens life quality. Modern information and communication technologies make possible offering new value added services beyond the typical scope of transport. For instance, ITS equipments spread over the city can be on the basis of a future urban ambient intelligence, allowing interactions among citizens, vehicles and public infrastructure. Therefore, ITS must be considered as a transversal problem with implications in many areas, and investments in any ITS technologies must take into account the full range of social impacts of these technologies [3]. In accordance with the findings of Adler and Blue [4], the most available and common specific ITS' benefits can be grouped into five sets of abilities which are implicit in the application of ITS.

1. Recognition, Communication and Learning with the driver;

2. Reduction Congestion or Improve Traffic Flow;
3. Decrease of Air Polluting Emissions and Positive Effect on the Environment;

4. Enhance of Productivity; and

5. Increase Safety.

Furthermore, ITS will not solve all of our transportation problems and might exacerbate some, especially environmental costs. Consequently, an overall transportation policy mix that addresses both system and economic-social inefficiencies must be comprehensively thought [3]. All these previous considerations suggest the necessity of tackling ITS necessities with a broader scope. Typically, the most common methodologies in socio-economic assessments are cost-benefit analyses (CBA), cost effective analyses, and multi-criteria appraisals, such as data envelopment analyses (DEA). However, the problem of these methodologies is that results are often difficult to compare as the different projects have often adopted different guidelines and cost and benefit evaluation methods [5]. Besides, ITS initiatives frequently fail due to the lack of agreement among manufacturers, developers, users and public authorities. This paper tries to fill this gap by proposing a scientific methodology known as concept mapping for the identification of new value added services with the participation of the main actors involved. Concept mapping is a conceptualization technique intended for reaching a consensus among participants though the application of several statistical techniques. The obtained results will show in the form of maps the common ideas and sensibilities of the target group.

The rest of the paper is organized as follows. The next section describes the methodology based on concept mapping techniques. The proposed methodology is then applied to the identification of new added value ITS services in section III. Finally, the conclusions are discussed.

\section{Methodology}

A concept map is a form of structured conceptualization that can be used by groups to develop the conceptual framework to guide an evaluation, an exercise, a plan, etc. [6]. Both quantitative and qualitative features are applied to develop a concept map. In this paper, the method proposed by Trochim will be followed [7]. This method considers a scientific procedure defined by a sequence of steps, and taking into account both quantitative and qualitative feature, 
such as numerical ratings and participants' previous experiences, respectively. This form of concept mapping is different from others like the one proposed by Novak and Gowin [8]. This method develops an informal drawing-based approach designed to help individuals draw maps that represent their ideas. But they are not specifically designed to work with groups, have no mechanism for aggregating ideas across individuals, nor utilize any statistical analytic methods. As a difference, concept-mapping as defined by Trochim shows the main categories of mathematically determined ideas derived from the participants' input. Each subset of ideas is represented on the map in cluster form. Those clusters that are closer to each other are said to be more directly linked. The maps represent the opinion of the participants. This procedure relies on expert opinions but with a statistical treatment of the compiled data to guaranty that conclusions are the result of the whole group conceptualization [9].

The considered concept mapping technique is laid out in the following steps [10].

1. Selecting and preparing the participants.

2. Brainstorming items (concepts) that deal with the topic matter.

3. Structuring and rating those items.

4. Representing those items on a concept map (using a multidimensional scale and clusters analysis).

5. Interpreting the maps.

At the start, the participants generate information through brainstorming in the form of statements. As part of the process, the data are structured and sorted, quantified, and analyzed using a double statistical analysis. The first statistical analysis is a multidimensional scaling, which aggregates the sorted data across all participants and develops the basic map. On this "point map" each statement is a point and statements that were piled together by more people are located closer to each other by the analysis. The second analysis is a cluster analysis, which takes the output of the multidimensional scaling (the point map) and partitions the map into groups of statements or ideas. The last step is the interpretation of the obtained maps.

\section{RESULTS}

The concept-mapping technique has been applied to identify the value added services that ITS could offer. The general procedure is based on the five steps outlined above.

\section{A. Selection and Preparation of the Participants}

One of the most important tasks in developing a concept map is deciding who will participate in the process. Experience shows that conceptualization is better when the process includes a wide range of experts [11]. A broad, heterogeneous participation helps to ensure that the different points of view will be considered, thus encouraging "constructing" the right conceptual framework.

For this study, 16 participants with contrasted working experience in ITS have been selected (i.e. experts in ITS, researchers, users, designers, centres staff of control of traffic, public authorities, etc). This number of people is within the adequate limits, between ten and twenty [7].

\section{B. Brainstorming}

The next stage consisted on identifying a list of items related to value added services ITS could offer. Using the brainstorming technique, the workgroup identified a list of 72 items, shown in Table 1.

1. Payment management in public vehicles

2 . Route management in goods and people transport systems

3. Routes management for emergency vehicles

4. Vehicle location and anti-theft alarm

5. Panic button against robbery, kidnappings

6. Automatic assistance request

7. Intelligence services for Mobile, PDA's, laptops

8. Optimum route identification using traffic information

9. Collision avoidance warning (in movement)

10. Object detection (for example, in parking)

11. Electronic payment in tolls/parking

12. Average speed control

13. Roadway sign guidance information

14. Driver information about nearby parkings (price, distance)

15. Driver information about road pavement conditions

16. Traveller information about potential hazards or route changes

17. Automatic speed limitation in dangerous areas

18. Electronic identification of vehicles in restricted areas

19. Automatic traffic light management for prioritizing emergency vehicles

20. Used capacity use detection and information in public vehicles

21. Information services for handicapped groups

22. Route information for handicapped persons

23. Information for no motorized vehicles

24. Location of nearest emergency services

25 . Taxi request with automatic petition location

26. Automatic vehicles lighting

27. Automatic management of public lighting

28. Automatic management traffic queues in traffic-lights

29. Incident detection and management

30. Public evens intelligent management system

31. Tourist information system

32. Local citizen information system

33. Vehicle maintenance warnings

34. Streets pollution levels

35. Contaminant vehicle emissions detection

36. Commercial vehicles electronic trace 


\begin{tabular}{|l|}
\hline 37. Special vehicles electronic trace \\
\hline 38. Warning of sleepiness \\
\hline 39. Automatic traffic signs detection \\
\hline 40. Dynamic Management of reversible lanes \\
\hline $\begin{array}{l}\text { 41. Surveillance systems for automatic vehicle and } \\
\text { pedestrians detection }\end{array}$ \\
\hline $\begin{array}{l}\text { 42. Intelligent traffic lights management for prioritizing } \\
\text { public transport vehicles }\end{array}$ \\
\hline $\begin{array}{l}\text { 43. Intelligent traffic lights management depending on the } \\
\text { traffic conditions }\end{array}$ \\
\hline $\begin{array}{l}\text { 44. Speed limits management in urban or inter-city routes, } \\
\text { depending on traffic conditions and rush hour }\end{array}$ \\
\hline $\begin{array}{l}\text { 45. Traffic lights management depending on people or } \\
\text { cyclist presence }\end{array}$ \\
\hline $\begin{array}{l}\text { 46. Variable public transport price depending on the day } \\
\text { hour. }\end{array}$ \\
\hline 47. Automatic detection of vehicles running red-lights \\
\hline 48. Automatic detection of vehicles running stops signs \\
\hline $\begin{array}{l}\text { 49. Driver information about visibility conditions (fog, } \\
\text { rains) }\end{array}$ \\
\hline 50. Automatc lighing in scarce visiblity conditis \\
\hline
\end{tabular}

50. Automatic lighting in scarce visibility conditions

51. Black box rewarding of vehicle indicators

52. Authentication of authorized staff for vehicle driving

53. Remote monitoring of routes and locations of commercial vehicles.

54. Automatic planning of commercial vehicles routes

55. Monitoring of load state and its environmental conditions

56. Automatic stability control of vehicles.

57. Aid systems for commercial vehicles coupling

58. Driver information about distances

59. Night vision system

60. Collision avoidance warning in crossroads

61. Lane-change warning system

62. Trip planning

63. Multimode travel coordination and planning

64. Information about services

65. Information on attractions

66. Appointment request service

67. Road condition information

68. Improvements of human sensory capacities

69. Hospitals and emergency medical services information

70. Real-time congestion information

71. Dynamic route selection

72. Services information directory

Table 1. List of identified items.

\section{Structuring and Rating the Items}

When a set of statements that describes the conceptual domain of the given topic is established, one must provide information about how they are interrelated and measured in relation to that topic. Both tasks make up the stage of item structuring throughout the concept-mapping development process.

The first task of the working group consisted of classifying the 72 statements in several groups based on their affinity with respect to some common value added services of ITS. Each of the participants applies his or her personal experience to define the number of groups and their components. A similarity matrix, defined as $S_{n x n}$ with $n=72$, is obtained as follows: the value of $(\mathrm{i}, \mathrm{j})$ element is equal to 1 if the ith and jth items are grouped together, and is equal to 0 otherwise. The total similarity matrix, defined as $T_{n x n}$, is obtained as the addition of all the similarity matrixes.

The second task consisted of rating each item according to the added value of the described service. The scaring options are defined as a Likert scale form, with a range of 1 to 5 , considering that $1=$ "little contribution", $5=$ "a lot of contribution", and the numbers in between referred to intermediate contributions. A "zero-contribution" score was not possible, since the brainstorming stage specifically asked for those ideas that contributed to offering the value added services. Therefore, for greater or little, all they had some contribution.

\section{Representing the Items in a Concept-Map Form}

A double analysis was performed using information about the following statistical analysis: a multidimensional scale and a cluster analysis.

Multidimensional scaling is a mathematical tool that uses proximities between objects, subjects, or stimuli to produce a spatial representation of these items. The proximities are defined as any set of numbers that expresses the amount of similarity or dissimilarity between pairs of objects, subjects, or stimuli. The object of multidimensional scale is to find the coordinates of the points in p-dimensional space so that there is a solid agreement between the observed proximities and the inter-point distances [12]. In concept mapping, this multidimensional scale sets up a point map that represents the set of declarations made during the brainstorming session. It is based on the results of the similarity matrix of the classified task. The most common approach used to determine the coordinates of the objects is an iterative process, commonly referred to as the Shepard-Kruskal algorithm [12].

The multidimensional scale gives the analyst a specific number $\mathrm{p}$ of dimensions that represent the set of points. If a one-dimensional solution is required, all the points will form one line. A two-dimensional solution will place the set of points on a plane. Interpretation of solutions with more than three dimensions is difficult. Therefore, when using concept maps, it's better to use two-dimensional graphs.

In this case, the different items were distributed on a twodimensional plane, starting from the similarity matrix, in such a way that the distance between the different items is inversely proportional to their affinity. That is, those items situated closer to each other are conceptually more closely related than those that are placed further from the plane. By representing the information in a two-dimensional space, the 
loss of information to obtain a less complicated interpretation of the information is accepted.

In the case studied, the multidimensional scaling provides the point map shown in Figure 1, obtained using MATLAB. Each point represents one of the 72 items from Table 1. The distance between points indicates the affinity of the two items/points. Closer items are more closely related to each other, while further points show a high level of dissimilarity.

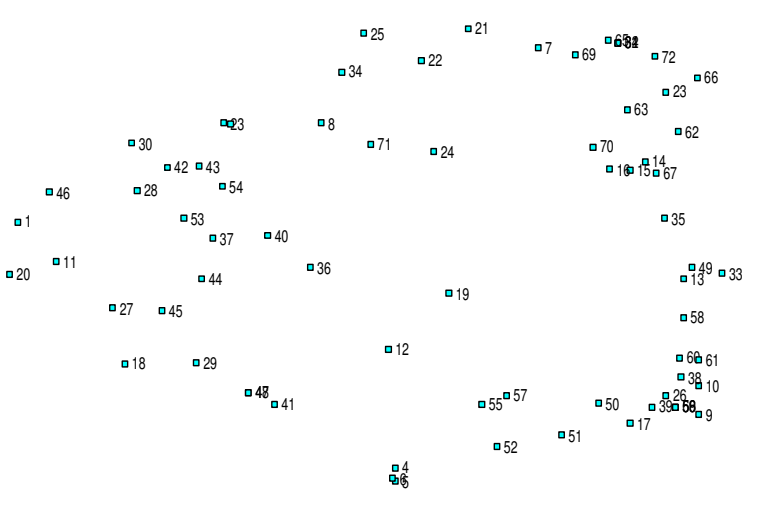

Figure 1. Point map.

Figure 2 shows the rating point map that includes the items' scoring made by the participants. Consequently, Figure 2 exposes the relative importance of each item with regard to its contribution as an ITS added value service. Once the two-dimensional representation of the 72 items has been obtained it is necessary to classify the items in homogeneous groups to categorize clusters of the value added services. This categorization is carried out with cluster analysis that organizes the information coming from the multidimensional scale, not from the Similarity Matrix [13]. Ward's algorithm is used for the cluster analysis since it offers more sensitive solutions and can be better interpreted than other estimates [14].

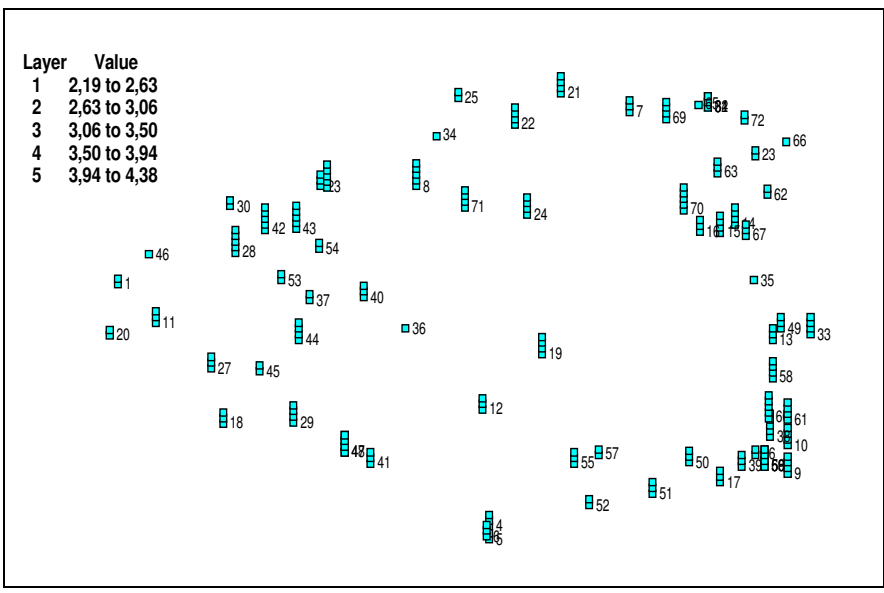

Figure 2. Rating point map.

At first, the cluster analysis considers each item as its own cluster, thus obtaining a solution of $\mathrm{N}$ clusters, in this case 72, corresponding to the number of identified items. For each level of analysis, Ward's algorithm combines two clusters until finally all the items are combined into just one cluster. Determination of the number of clusters to be used in the final solution is important. Subsequently, discretion is required when examining the different types of possible cluster solutions to decide which ones make sense. As a rule of thumb the number of clusters that errs by excess, rather than by defect, is used; in other words, a larger number of clusters is preferred to having a cluster containing heterogeneous concepts.

The obtained result is shown in Figure 3 that includes the different groups highlighted by the cluster analysis. These clusters will define the resulting value added services that ITS could offer.

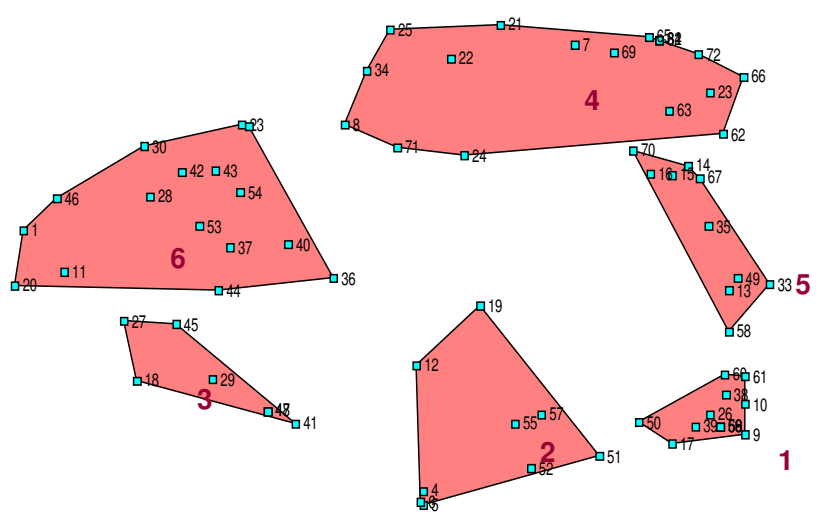

Figure 3. Cluster map

The final analysis requires an average score for each participant and for each cluster, generating a rating cluster map. In the case studied, the inclusion of the scores for each cluster leads to the representation of Figure 4.

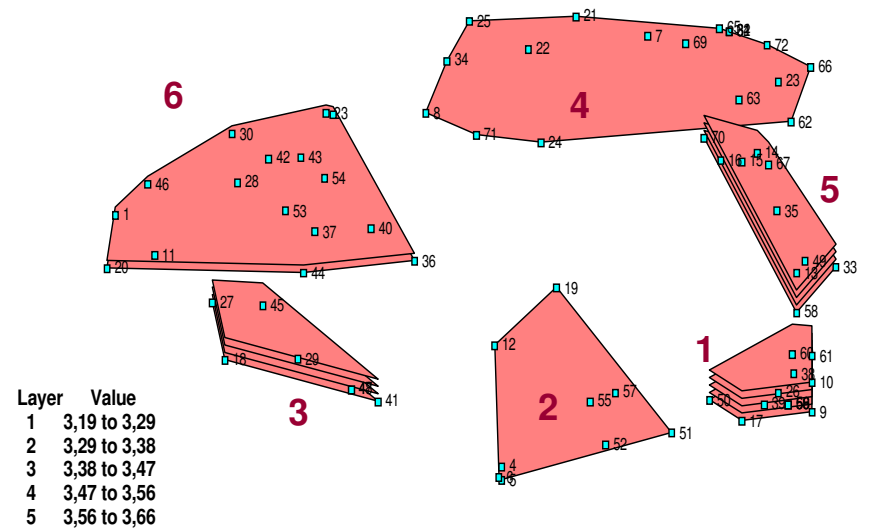

Figure 4. Rating cluster map

\section{E. Interpretation of Maps}

In order to interpret the maps, a final workgroup was organized. Generally, the results derived from the cluster analysis are more difficult to interpret than those from the multidimensional scale. The cluster analysis is seen as an indicator. At times, one would like to "visually arrange" the clusters into sensitive parts so that the multidimensional 
space could be interpreted more easily. The key is to maintain the integrity of the multidimensional scale results by achieving a solution that will not allow the clusters to overlap. A consensus of the names given to the different clusters must be reached, using as a starting point those names given to the groups by the participants.

Analyzing the map from Figure 4, three big regions can be estimated, highlighted in Figure 5 and Table 2.

\begin{tabular}{|c|c|c|}
\hline Region & Cluster & Denomination \\
\hline \multirow{3}{*}{$\begin{array}{l}\text { Region 1: } \\
\text { Safety \& } \\
\text { Security }\end{array}$} & Cluster 1 & In-vehicle Safety \\
\hline & Cluster 2 & In-vehicle Security systems \\
\hline & Cluster 3 & Third party vehicle safety \\
\hline \multirow{2}{*}{$\begin{array}{l}\text { Region 2: } \\
\text { Information } \\
\text { Services }\end{array}$} & Cluster 4 & $\begin{array}{l}\text { Routes and services } \\
\text { information management }\end{array}$ \\
\hline & Cluster 5 & Traffic information \\
\hline $\begin{array}{l}\text { Region 3: ITS } \\
\text { Management }\end{array}$ & Cluster 6 & $\begin{array}{l}\text { Intelligent management of } \\
\text { public infrastructures }\end{array}$ \\
\hline
\end{tabular}

Table 2. Cluster and region names.

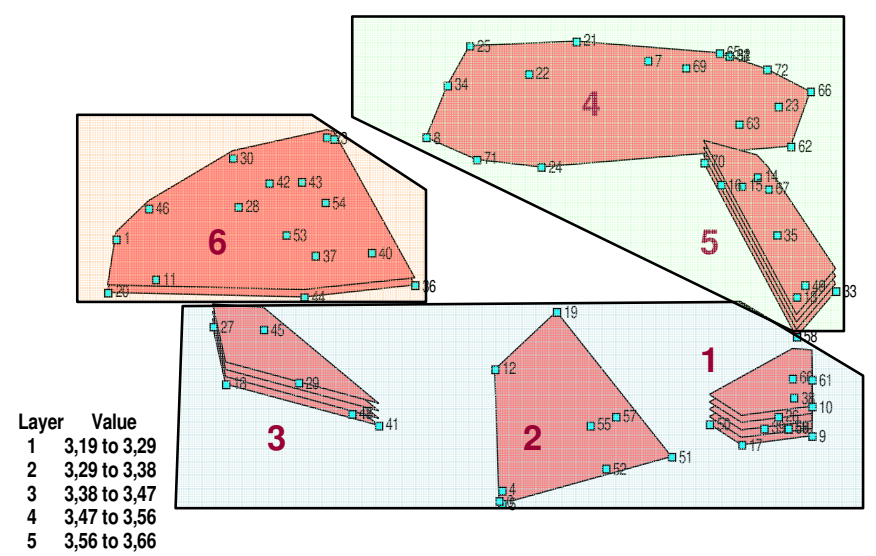

Figure 5. Regions in the cluster map.

The first region, placed in the bottom part of Figure 5, refers to those tools designed to guarantee the security, not only to prevent drivers from accidents or thefts, but also to ask for aid without needing to locate a phone, know the appropriate phone number or even know the current location. It will be named in a generic way "Safety \& Security", and agglutinates the clusters shown in Table 2.

The second region placed in the top part of Figure 5 refers to those tools which enable drivers to access to information about traffic, routes, services, in order to make efficient their journeys. This region is generically named "Information" and is formed by two clusters, as shown in Table 2 .

The last region is placed in the low left part of Figure 5. It refers to those tools which could help the authorities to manage traffic and public transport services. This region is called "ITS Management" and it is formed by one cluster (see Table 2).

Finally, from the cluster rating map of Figure 4, there can be obtained the relative weight of the different matters that shape the ITS services. In the low left corner of this figure, the meaning of each layer is shown. The lower values correspond to cluster 2, "Security systems on board", and cluster 4, "Information on point of interest". The rest of the clusters are highly valued respect the previous ones. That is because these refer to safety and preventing from accidents. The relative weight of each cluster can be used as a starting point when deciding the added value services to invest in.

The obtained results summarize the main trends in transportation systems research and applications. Three wide regions have been identified. Although the first one refers to safety and security, the two highest scored clusters are related to safety. In particular, one of them is focused on invehicle safety issues and the other one in third party vehicle safeties. Traditionally, a great deal of research has been dedicated to improve in-vehicle safety systems in issues like vision enhancement, vehicle stability, driver condition monitoring or safety impacting [15]. This interest in safety is justified by reports like the ones published by World Health Organization about road traffic injury prevention [16]. These reports underscore the concern that unsafe road traffic systems are seriously harming global public health and development, and contend that the level of road traffic injury is unacceptable and largely avoidable. For instance, the economic cost of road crashes and injuries is estimated to be $1 \%$ of gross national product in low-income countries, $1.5 \%$ in middle-income countries and $2 \%$ in high-income countries, being US\$ 518 billion per year the estimated global cost. By contrast, these reports emphasize that very little money is invested in research and development funding for preventing road traffic incidents, and deduce that more attention must be paid in road traffic security research area. In this sense, new research lines are currently shifting the sensing capability from onboard sensors to inter-vehicle communications [17]. This technology is known as Vehicle to Vehicle $(\mathrm{V} 2 \mathrm{~V})$ communication, and in the case of safety refers the exchange of data over a wireless network that provides critical information which allows each vehicle to perform calculations and issue driver alerts, or driver advisories, or take pre-emptive actions to avoid and mitigate crashes [18].

The second identified area corresponds to information services, and, in this case, the most valued cluster is about traffic information. This issue can be included in the ATIS (Advanced Traveller Information Systems) ITS technologies. In this case, the challenge for the automotive industry is the in-vehicle integration of nomadic devices. Nomadic devices refer to all portable devices that the driver brings into the vehicle and uses while driving, e.g., mobile phone, PDA, [19].

Finally, the last identified area is related to public infrastructures, which can play an important role in modern intelligent transportation systems. Today, many traffic equipments are spread over the city and connected with traffic control centres through urban data networks. From traffic regulators to surveillance cameras, all these equipments are provided with enough computing power to interact with the environment. In particular, they can interact with vehicles leading to the so called vehicle to infrastructure technology (V2I), [20]. The V2I architecture allows vehicles to communicate with some urban and roadway infrastructure 
offering new services like intelligent traffic signaling, speed warnings, traffic information services, etc. [21].

\section{CONCLUSIONS}

This paper refers to the development of a scientific method to identify the added value services that ITS technologies should offer. This methodology guarantees that different points of view are reflected in the final result. It is true because people belonging to different areas (academic, drivers, traffic systems designers, etc.) have taken part in the development of the maps. Moreover, this people know the reality of the environment, so they are able to proportionate solutions to concrete situations.

With all this in mind, the added value services that ITS can offer have been obtained. The final result brings six added value services which can be grouped into three areas: Safety and security, Information, and ITS Management. It has also been identified that those services referring to improving safety and to accessing to information on traffic are more valuable than those referring to security or information on points of interest. This result confirms previous appreciations.

\section{ACKNOWLEDGMENT}

This work has been supported by the Spanish Ministry of Education and Science (Research Project with reference DPI2007-60128) and the Consejería de Innovación, Ciencia y Empresa (Research Project with reference P07-TIC02621).

\section{REFERENCES}

[1] M. Slinn, P. Matthews, \& and P. Guest, Traffic Engineering Design, Second Edition, Principles and Practice, pp. 209-217, 2005.

[2] S. Toral, M. Vargas, F. Barrero, \& M. G. Ortega, "Improved Sigmadelta Background Estimation for Vehicle Detection", Electronics Letters, Vol. 45, no. 1, pp. 32-33, 2009.

[3] B. Kanninen, "Intelligent Transportation Systems: an economic and environmental policy assessment", Transportation Research, Part A, Vol. 30, no. 1, pp. 1-10, 1996.

[4] J. Adler, \& V. Blue, "Toward the design of intelligent traveller information system", Transportation Research, Part C, Vol. 6, no. 3, pp. 157-172, 1998.

[5] J. Zhicai, W. Jianping, \& M. McDonald, "Socio-Economic Impact Assessment of Intelligent Transport Systems", Tshinghua Science and Technology, Vol. 11, no. 3, pp. 339-350, 2006.
[6] S. L. Toral, M.R. Martínez-Torres, F. Barrero, S. Gallardo, M.J. Durán, "An Electronic Engineering Curriculum Design based on Concept-Mapping Techniques", International Journal of Technology and Design Education, Vol. 17, no. 3, pp. 341-356, 2007.

[7] W. M. K. Trochim, "An introduction to concept mapping for planning and evaluation", Evaluation Program Planning, Vol. 12, no. 1, pp. 1$16,1989$.

[8] J.D. Novak, \& D.B. Gowin, D. B. Learning How to Learn. New York: Cambridge University Press, 1984.

[9] S. L. Toral Marín, M. R. Martínez Torres, F. J. Barrero García, S. Gallardo Vázquez, E. Vargas, V. González Ayala, "Planning a Master's level Curriculum according to Career Space Recommendations Using Concept Mapping Techniques", International Journal of Technology and Design Education, Vol. 16, no. 3, pp. 237-252, 2006.

[10] D.G. Kolb, \& D. M. Shepherd, "Concept mapping organizational cultures”. J. Manag. Inquiry, Vol. 6, no. 4, pp. 282-295, 1997.

[11] M. R. Martínez-Torres, F. J. Barrero García, S. L. Toral Marín, S. Gallardo Vázquez, "A Digital Signal Processing Teaching Methodology Using Concept-Mapping Techniques", IEEE Transactions on Education, Vol. 48, no. 3, pp. 422-429, 2005.

[12] L. Fahrmeir, \& A. Hamerle, Multivariate Statistiche Verfahren, Berlin, Germany, De Gruyter, 1984.

[13] B. S. Everitt, Cluster Analysis. New York, Halsted, 1993.

[14] J. H. Ward, "Hierarchical grouping to optimize an objective function”, J. Amer. Statistical Assn., Vol. 58, pp. 236-244, 1963.

[15] M. Bertozzi, A. Broggi, M. Cellario, A. Fascioli, P. Lombardi, M. Porta, "Artificial vision in road vehicles", Proceedings of the IEEE, Vol. 90, Iss. 7, pp. 1258-1271, 2002.

[16] World Health Organization, The World report on road traffic injury prevention. Geneva, Peden M. et al. Eds., World Health Organization, 2004

[17] L. Li, J. Song, F.-Y. Wang, W. Niehsen, N.-N. Zheng, "IVS 05: new developments and research trends for intelligent vehicles", IEEE Intelligent Systems, Vol. 20, Iss. 4, pp. 10-14, 2005.

[18] X. Yang, L. Liu, N. H.Vaidya, F. Zhao, "A vehicle-to-vehicle communication protocol for cooperative collision warning", The First Annual International Conference on Mobile and Ubiquitous Systems: Networking and Services, MOBIQUITOUS, pp. 22-26, 2004.

[19] A. Amditis, A. Polychronopoulos, L. Andreone, and E. Bekiaris, "Communication and interaction strategies in automotive adaptive interfaces", Cognition, Technology \& Work, Vol. 8, no. 3, pp. 193199, 2006.

[20] H. Wu, M. Palekar, R. Fujimoto, J. Lee, J. Ko, R. Guensler, M. Hunter, "Vehicular networks in urban transportation systems", Proceedings of the 2005 national conference on Digital government research, pp. 9-10, 2005.

[21] J. Miller, "Vehicle-to-vehicle-to-infrastructure (V2V2I) intelligent transportation system architecture", IEEE Intelligent Vehicles Symposium, pp. 715-720, 2008. 